\title{
Termik Santral Atığı Mikro Küreciklerin Özelliklerinin İncelenmesi Ve Ekzotermik Besleyici Hammaddesi Olarak Kullanılabilirliğinin Araştırılması
}

\author{
${ }^{* 1}$ Adem Demir, ${ }^{2}$ Özlemnur Sezer, ${ }^{2}$ Neşe Bayar ve ${ }^{2}$ Muzaffer Eyüpoğlu \\ ${ }^{1, S a k a r y a}$ Uygulamalı Bilimler Üniversitesi Teknoloji Fakültesi Metalurji ve Malzeme Mühendisliği \\ Bölümü Sakarya, Turkey \\ ${ }^{2}$ Eyüpoğlu Metalurji Düzce,Turkey
}

\begin{abstract}
Özet
Termik santrallerde enerji kaynağı olarak düşük kalitede linyit kömürleri kullanılmaktadır. Bu linyit kömürleri ocaktan çıkarılırken yer kabuğundan çeşitli minerallerle katışı olarak çıkarılırlar. Çoğunluğu alümina ve silikat esaslı mineraller olan bu katışılkar kömürün yanması ile çeșitli reaksiyonların oluşmasına ve faz değişimlerinin meydana gelmesini sağlar ve uçucu kül denen yanma reaksiyonu ürünleri açığa çıkar. Bu yanmayan mineraller yanmış gazlar veya alev ettekisiyle boşluklu form alırlar ve alttaki su tankında son şeklini kazanırlar. Bu çalışmada bu reaksiyon ürünü içi boşluklu mikro kürecikler analiz edilerek incelendi. SEM görüntüleme XRD ve XRF faz analizleri yapıldı. Bu analizler sonunda mulit fazında içi boşluklu mikro küreciklerin olduğu kömür cürufu griti olduğu ve yoğunluklarının $1 \mathrm{gcm}-3$ altında olduğu tespit edilmiştir.
\end{abstract}

Anahtar Kelimeler: Uçucu Küller, mikro kürecikler, ekzotermik besleyiciler

\begin{abstract}
Low-quality lignite coal is used as an energy source in thermal power plants. These lignite coals are removed from the earth crust and mixed with various minerals. These impurities, mostly alumina and silicate-based minerals, cause the formation of various reactions and phase changes by combustion of coal and the combustion reaction products called fly ash are released. Some of these non-combustible minerals take hollow form by burnt gases or flame and they take their final shape in the bottom water tank. In this study, this reaction product, hollow microspheres was examined by analysing the. SEM imaging XRD and XRF phase analysis were performed. At the end of these analyses, it was found that there was a coal slag grit with microspheres in the mulit phase and the density was below $1 \mathrm{gcm}-3$.
\end{abstract}

Key Words: Fly Ashes, microspheres, exothermic riser

\section{Giriş}

Kömür yanmasından elde edilen mikro kürecikler, katı atıkların küçük ama önemli bir bölümünü oluşturur. Düşük yoğunlukları ve yüksek mekanik özellikleri gibi bazı ayırt edici özelliklerden dolayı mikro kürecikler, birçok sanayi dalında uygulanmış ve günümüzde, aranan kıymetli bir ürün haline gelmiştir[1,2].

Linyit kömürü öğütülerek kazana pülverize halde püskürtülerek yakılır Yanma sırasında bu alümina silikat maddeler yanmaz ve $1750^{\circ} \mathrm{C}$ sicaklıkta sıvı faza geçerek sentezlenerek kazan dibinde bulunan su tankında toplanır. Bir kısmı da uçucu kül olarak baca gazlarıyla ayrışır, filtre edilerek ayrı bir yerde toplanır. Mikro kürecikler kömür yakan termik santrallerin bir yan ürünü olan içi boş seramik mikro kürelerdir. Termik santrallerde pulverize kömür 
yakıldığında, uçucu kül üretilir. Mikro kürecikler daha hafif parçacıklardır uçucu kül içinde bulunurlar ve uçucu külün ağırlıkça yaklaşık\% 1-2'sini oluştururlar[3-5].

Kazanın içindeki yanma kömürün içindeki mineralleri eritir. Mineral bileşiminin yansıra mikro küreciklerin nasıl oluştuğunu ve hangi spesifik faktörlerin olduğunu anlamak önemlidir. Kazan sıcaklığı veya bazı belirli elementlerin miktarı bu süreci ilerletir ve uçucu küllerin verimlerini arttırır. Kömürün yanması için öncelikle içindeki nemin ve uçucu ürünlerin gaz haline dönüşerek uçurulması gerekir. Bu işlemden kömüre çar kömürü denir ve ancak çar kömür oluştuktan sonra pulverize edilerek yanma başlar[5-8].

Bu çalışmanın amacı, kimyasal ve yapısal olarak mikro kürecikleri karakterize etmektir. Ana faktörler yanma sürecinin kendisi ile ilgili olabilir. Bu nedenle, bu çalışmada sadece kazanda meydana gelen termodinamik süreçler sonucu oluşan mikro küreciklerin morfolojisi ve kimyasal bileşim üzerine odaklanılmış ve ayrıca bu morfolojideki içi boş seramik partikülün ekzotermik besleyici için faydalı bir refrakter malzeme olabileceği araştırılacaktır.

\section{Deneysel Çalışmalar}

Ukrayna termik santralinin atıklarından olan uçucu küller su içine çöktürülmektedir. Yoğunluğu sudan yüksek olan tanecikler dibe çökerken sudan yüksek olan mikro kürecikler. Su yüzünde yüzmektedirler. Bu atıkların yaklaşık $\% 2$ si mikro kürecik olarak su yüzünde kalır ve özel bir işlemlerle toplanır. Toplanan kürecikler $600^{\circ} \mathrm{C}$ sicaklıkta 2 saat tutularak içinde organik kalıntılar yakılır ve gaz formunda atılır. Katışıklarından ayrılan mikro kürecikler elenerek boyut sinıflandırmasına tabi tutulur ve piyasaya sürülür. $\mathrm{Bu}$ işlemden geçen uçucu küllerden numune alındı ve çeşitli analizlere tabi tutuldu. Tarama Elektron Mikroskopu (SEM) incelemeleri Elementel analiz (EDS), X-1sınları Floresans ve (XRF) Faz Analizleri yapıldı.

\section{Sonuçlar ve İrdelenmesi}

\subsection{Tarama Elektron Mikroskopu (SEM) Analizi}

Termik santralda kömürün yanması sonucu açığa çıkan kömür cürufunun taramalı elektron mikroskopu görüntü analizleri yapıldı. Şekil 1 de görüldüğ̈̈ gibi kömür cürufunun taneciklerinin mükemmele yakın küresel olduğu gözlenmektedir. Tanelerin çapı yaklaşık 50 mikron ile 250 mikron arasında değişmektedir. Bu taneciklere literatürde uçucu küllere de denilmektedir.

SEM incelemeleri sonucu kürelerin içi boşluklu ve yani gözenekli olduğu tespit edilmiştir. Özellikle Şekil 1 d'ye dikkatli bakıldığında büyük küreler içinde küçük küreciklerden oluşan bir yapı olduğu söylenebilir. Bu şekildeki bir tanecik yapısının yoğunluğu düşük olacağından hacimsel olarak aynı boyut dağılımı gösteren kumlara göre daha büyük hacim kaplayacaktır. Literatürde bu kürelerin görünür yoğunlukları $0,95 \mathrm{gr} / \mathrm{cm} 3$ 'ün altında olduğu bildirilmektedir. Dolayasıyla bu mikro kürelerin hacminin üçte ikisinden fazlasının boşluk olması gerekmektedir. Elde edilen SEM görüntülerinde boşluklu olduğu açikça görülmektedir. İncelenen numunenin SEM görüntü analizleri, numunenin ISO 11126-4 standardında belirtilen kömür cürufu morfolojisi ile uyumlu olduğunu göstermektedir 


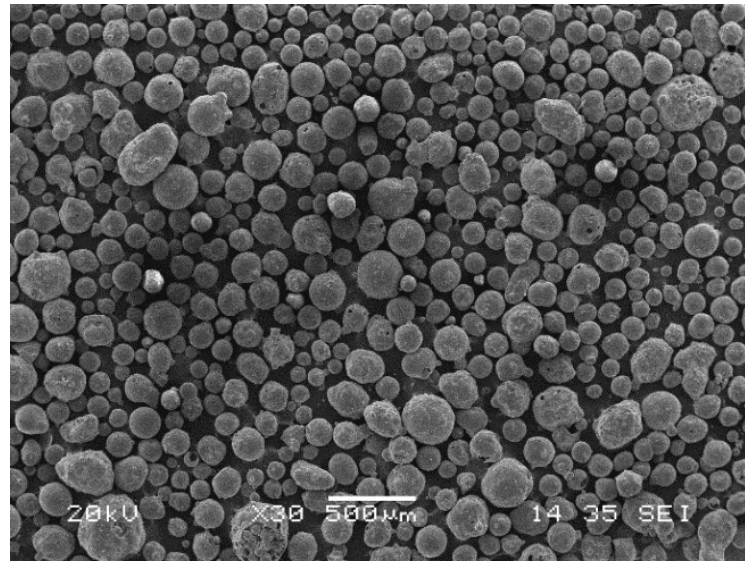

(a)

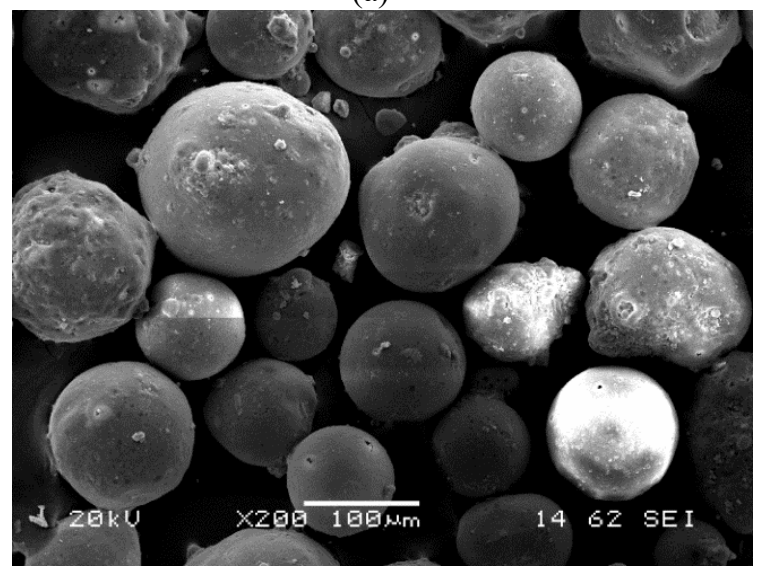

(c)

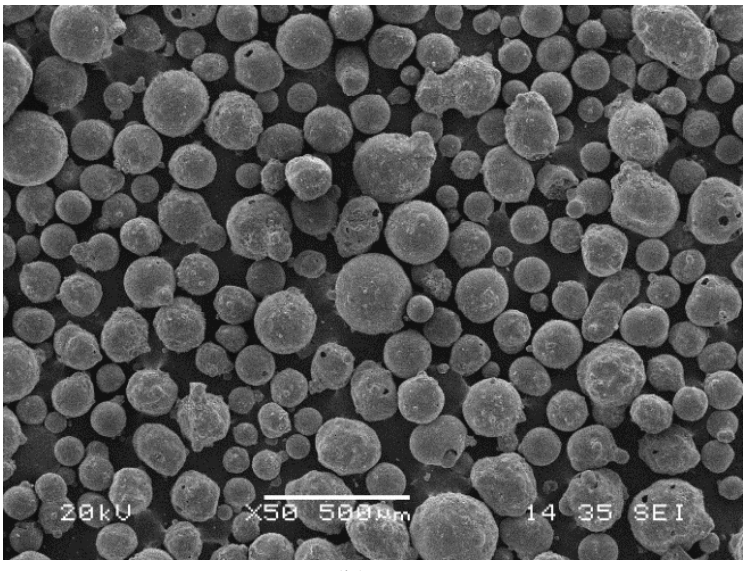

(b)

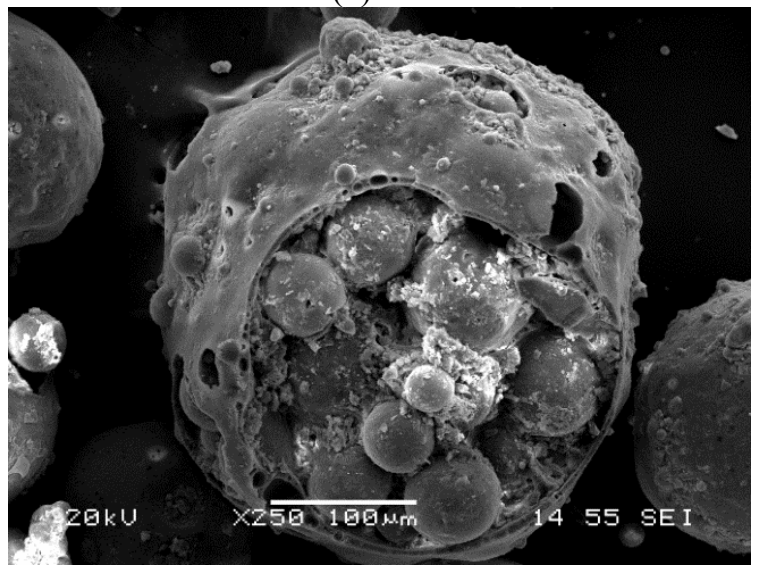

(d)

Şekil 1 Mikro küreciklerin tarama elektron mikroskop (SEM) görüntüleri a,b) genel dağılım c)küresel ve kısmen pürüzsüz yüzey morfolojisi d)iç içe geçmiş bos kürecikler.

\subsection{Elementel Analiz (EDS)}

Kömür cüruflarının elementel analizleri tarama elektron mikroskobu cihazında ayrıca yapılmış ve aşağıdaki sonuçlar elde edilmiştir. Kömür cürufu taneleri üzerinde numaralandırılan noktalarda hangi elementlerin hangi oranlarda olduğu ölçülmüş ve resimlerin altındaki sonuç grafikleri ve tabloları elde edilmiştir. Bu sonuçlara göre ana elementler olarak alüminyum silisyum ve oksijen elementlerine rastlanmıştır. Dolayısıyla bu elementel sonuçlar bu mikro kürelerin bu üç elementin ikili ya da üçlü bileşiminden oluştuğunu göstermektedir. Doğada kömür çıkarılırken Alüminyumsilkat esaslı killerde beraberinde çıkarılmaktadır. 

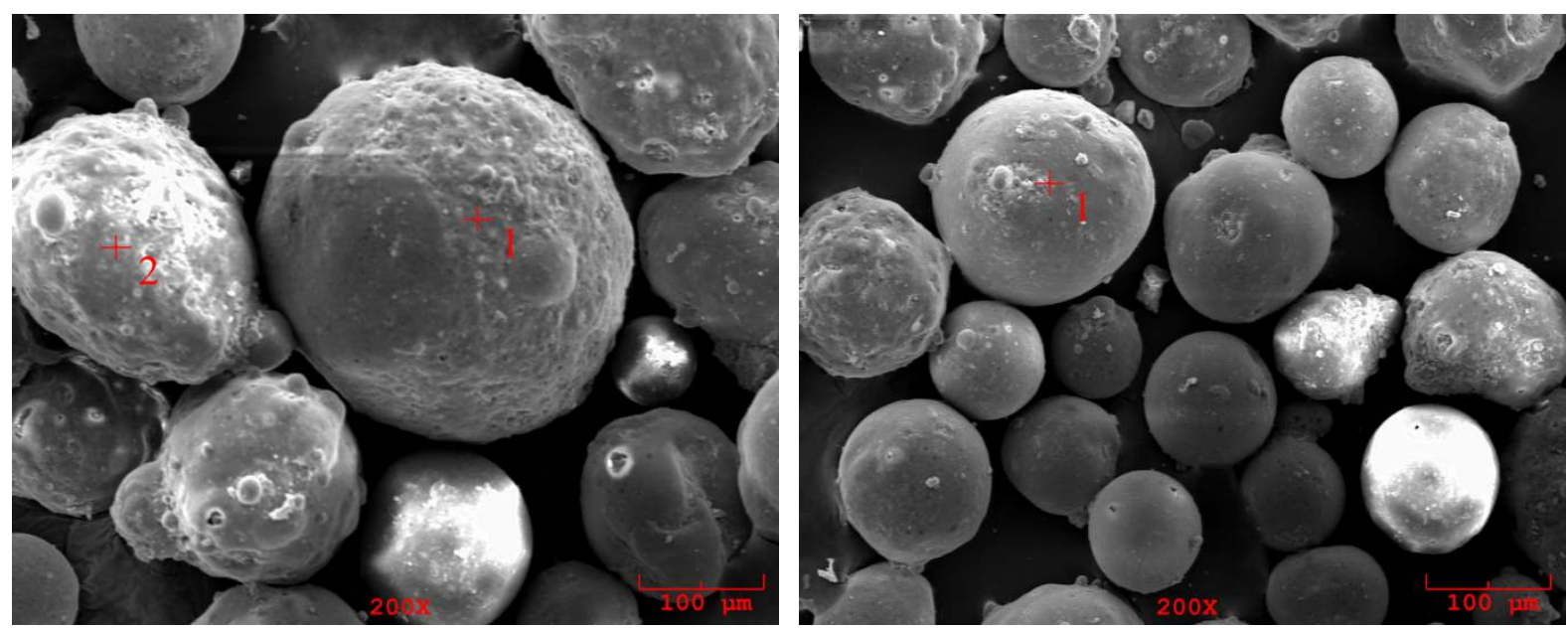

Şekil 2. EDS analizi alınan noktalar.

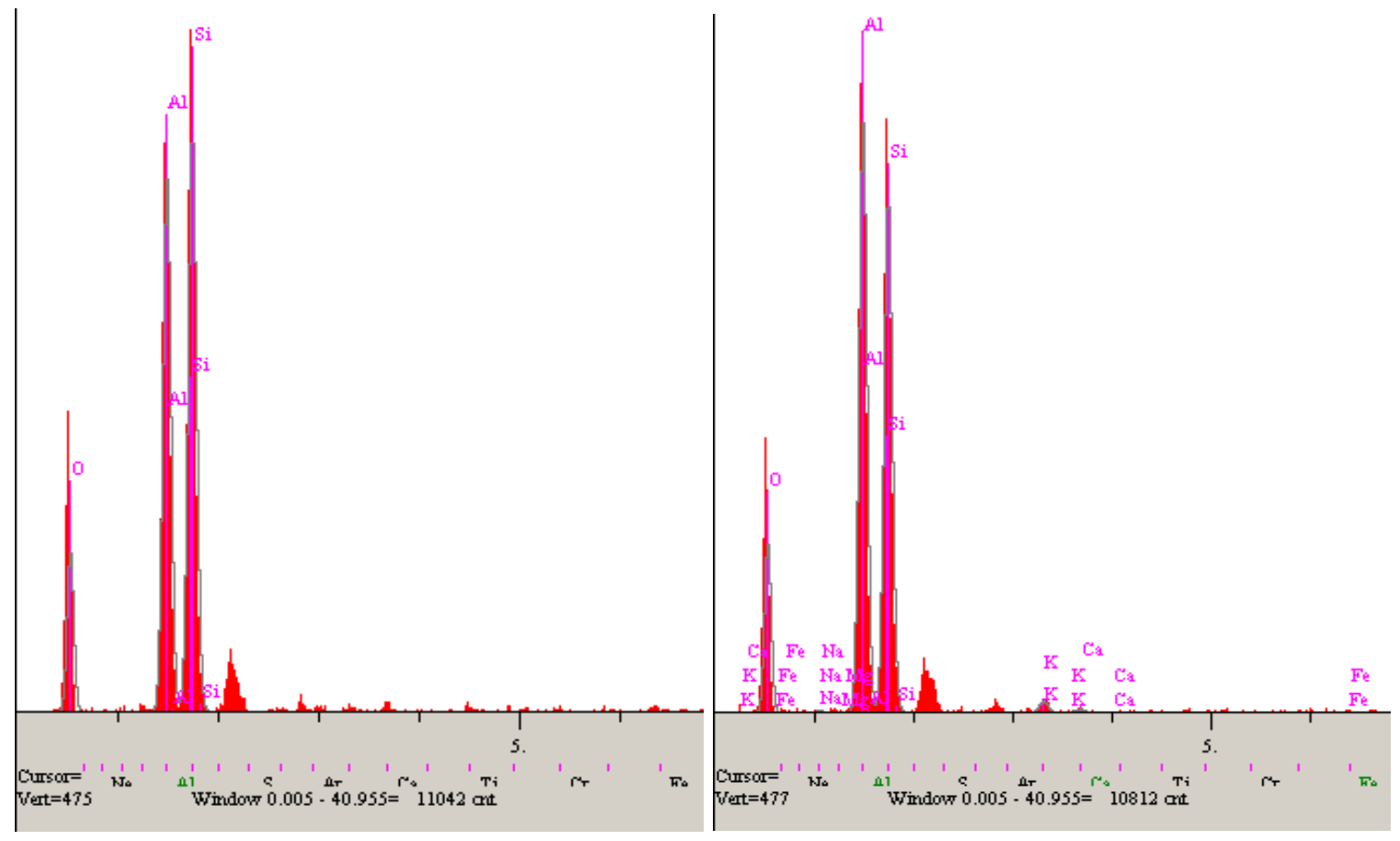

Şekil 3. EDS analiz sonuçları

Tablo 1. Orantısal EDS sonuçları

\begin{tabular}{|l|l|l|l|l|l|}
\hline Elt. & Line & $\begin{array}{l}\text { Intensity } \\
(\mathbf{c} / \mathbf{s})\end{array}$ & $\begin{array}{l}\text { Error } \\
\text { 2-sig }\end{array}$ & Conc & Units \\
\hline $\mathrm{O}$ & $\mathrm{Ka}$ & 99.05 & 6.293 & 33.395 & wt.\% \\
\hline $\mathrm{Na}$ & $\mathrm{Ka}$ & 1.72 & 0.829 & 0.191 & wt.\% \\
\hline $\mathrm{Mg}$ & $\mathrm{Ka}$ & 1.31 & 0.723 & 0.104 & wt.\% \\
\hline $\mathrm{Al}$ & $\mathrm{Ka}$ & 400.94 & 12.660 & 28.849 & wt.\% \\
\hline $\mathrm{Si}$ & $\mathrm{Ka}$ & 364.72 & 12.075 & 35.999 & wt.\% \\
\hline $\mathrm{K}$ & $\mathrm{Ka}$ & 9.48 & 1.947 & 0.931 & wt.\% \\
\hline $\mathrm{Ca}$ & $\mathrm{Ka}$ & 3.09 & 1.111 & 0.302 & wt.\% \\
\hline $\mathrm{Fe}$ & $\mathrm{Ka}$ & 1.32 & 0.727 & 0.230 & wt.\% \\
\hline & & & & 100.000 & wt.\% \\
\hline
\end{tabular}


Kömürün yanmasıyla kil minerali camsı sıvı oluşturarak önce damlacık sonrada kürecikler oluşturmuştur. $\mathrm{Bu}$ nedenle EDS analizlerinde Şekil 3 de görüldüğü gibi baskın olarak alüminyum, silisyum ve oksijen rastlanmıştır.

\subsection{X-ısınları Floresans ve (XRF) Faz Analizi}

Tablo 2 de eledi edilen XRF sonuçları incelendiğinde, kömür cürufu numunesinde ana faz olarak \% 55.37 silika $\left(\mathrm{SiO}_{2}\right)$ ve \% 37,37 alümina $\left(\mathrm{Al}_{2} \mathrm{O}_{3}\right)$ bulunmaktadır. Bunların dışında eser miktarda demir oksit, kalsiyum oksit, titanyum oksit, potasyum oksit, magnezyum oksit, fosfor oksit, klor, kükürt oksit ve baryum oksit bulunmaktadır.

EDS sonuçlarında majör miktarda tespit edilen $\mathrm{Al}$, Si ve $\mathrm{O}$ elementleri XRF analizinde görüldüğü gibi bu üç elementin bileşikleri olan $\mathrm{SiO}_{2}$ ve $\mathrm{Al}_{2} \mathrm{O}_{3}$ çoğunluk oran $\% 92.54$ oluşturmaktadır.Yine EDS analizlerinde tespit edilen $\mathrm{Na}, \mathrm{Mg}, \mathrm{K}, \mathrm{Ca}$ ve Fe XRF testinde bu elementlerin yine EDS de tespit edilen oksijenle bağ yapmış durumdadır. Ancak Bu elementlerin oksitleri alüminyum ve silisyumun oksitlerine göre çok daha azdır. En yüksek olan demir oksit \% 1.997 ölçülmüştür. Sonuç olarak XRF analizleri sonucu ölçülen değerler ISO 11126-4 belirtilen faz değerleri ile örtüşmektedir.

Tablo2. XRF sonuçları

\begin{tabular}{lrl} 
Formula & Conc... & Status \\
\hline $\mathrm{SiO} 2$ & 55.37 & XRF 1 \\
$\mathrm{A} 2 \mathrm{O} 3$ & 37.37 & XRF 1 \\
$\mathrm{Fe} 2 \mathrm{O} 3$ & 1.997 & XRF 1 \\
$\mathrm{CaO}$ & 1.25 & XRF 1 \\
$\mathrm{TiO} 2$ & 1.19 & XRF 1 \\
$\mathrm{K} 2 \mathrm{O}$ & 0.810 & XRF 1 \\
$\mathrm{Na} 2 \mathrm{O}$ & 0.605 & XRF 1 \\
$\mathrm{MgO}$ & 0.384 & XRF 1 \\
$\mathrm{P} 2 \mathrm{O} 5$ & 0.379 & XRF 1 \\
$\mathrm{Cl}$ & 0.315 & XRF 1 \\
$\mathrm{SO} 3$ & 0.164 & XRF 1 \\
$\mathrm{BaO}$ & 0.16 & XRF 1
\end{tabular}

\subsection{X-ışınları (XRD) Analizi}

Kömür cürufu numunesi X-1şınları faz analiz cihazında incelendiğinde aşağıdaki X ışınları kırınım grafiği elde edilmiştir. Bu grafik yapının tamamen mullit olduğunu söylemektedir. Mullit bir alümina Silika bileşiminden oluşan ayrı bir fazdır. Dolayısıyla XRF cihazında tespit edilen $\mathrm{Al}_{2} \mathrm{O}_{3}$ ve $\mathrm{SiO}_{2}$ denge diyagramında bilinen fazları mullit fazını oluşturmuştur. Dolayısıyla şekil 1 de görülen bu küreler ana faz olarak mullit seramiğinden oluşmaktadır. Diğer fazlar XRD faz analizinde tespit edilemeyecek kadar azdır. XRD cihazı yaklaşık \% 5'in altında olan fazları tespit edememektedir. Dolayısıyla numunemiz tek fazlıymış tespit 
edilmiştir. Literatürde mullit fazı \%39 Alümina ve \%61 Silika seramiklerinin bir ara bileşiği olarak verilmektedir. Bu nedenle XRF de alümina ve silika ayrı vaz XRD de ise ikisinin bileşimi mullit fazına rastlanmıştır.

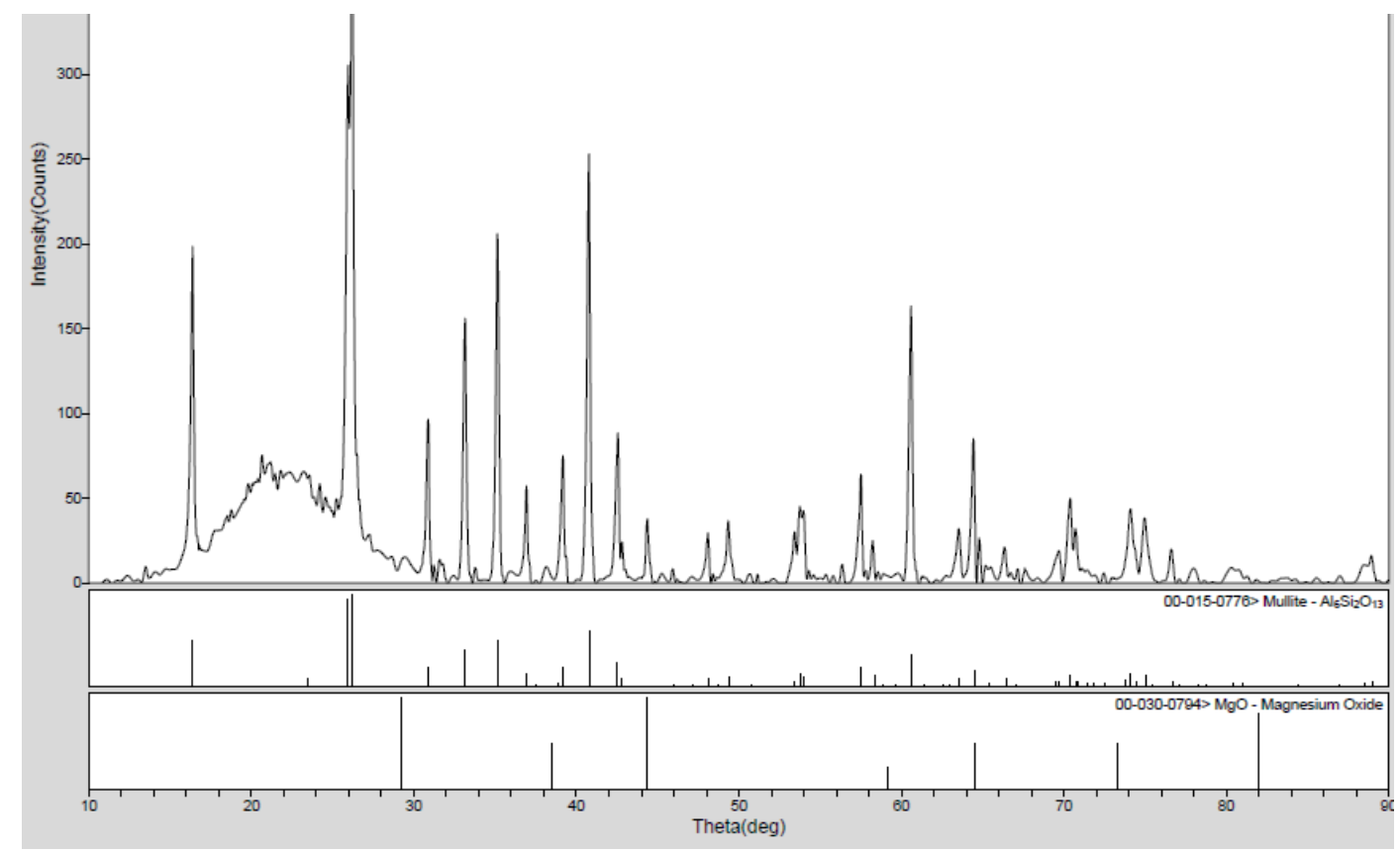

Şekil 5. XRD analiz sonuçlar.

\subsection{Besleyici Hammaddesi Olarak Uygunluğu}

Döküm sektörüne malzeme üreten firmalar mini besleyici yaptıklarında doğal silika kumu kullanmaktadır. Silika kumu yanma sırasında besleyicinin formunu korumasını ve gözenekleri sayesinde arasındaki kimyasalların yanmasına imkan sağlamaktadır. Ancak silika kumunun yoğunluğunun yüksek olması besleyicilerin ağır olmasına ve daha fazla kimyasal kullanılmasına yol açmaktadır. Yapılan ön çalışmada içi boş mikro küreciklerin izolasyon etkisi göstererek sıvı metalin 1sısını daha uzun süre tutuğu ve besleme etkisini daha uzun süre gösterdiği görülmüştür. Bu nedenle düşük yoğunluklu termik santral atığı mikro kürecikler besleyici yapımında kullanılırsa kullanılan kimyasallardan en az yarı yarıya tasarruf edileceği düşünülmektedir.

\subsection{TS EN ISO 11126-4 Standardının Kapsamı}

TS EN ISO 11126-4 standardında tanımlan kömür cürufu griti çelik yüzeylerin temizlenmesi için kullanılan metalik olmayan kumlama malzemesi olarak kullanılmasını ve kömür cürufunun özelliklerini kapsamaktadır. Bu standartta çelik yüzeyler boya öncesi bir yüzey temizleme ve pürüzledirme işleminden geçmektedir. $\mathrm{Bu}$ işlemi yapmak için kumlama malzemeleri çelik yüzeylere hızla püskürterek yüzeyler temizlenmektedir. $\mathrm{Bu}$ aşındırıcı malzemelere grit denmektedir. Normal şartlarda kumlama küçük çelik balyalarla yapılır ancak yağlı yüzeyleri temizlemede sıvı emme özelliği olan ve çelikten daha sert malzemeler tercih edilmesi seramik esaslı gritlerin kullanılmasına yol açmıştır. Dolayısıyla TS EN ISO 11126-4 
standardı kömür cürufu gritinin bu özelliğinden dolayı çelik yüzeylerde kumlama(grit) malzemesi olarak uygunluğunu tescil etmekte ve bunla ilgili esasları belirlemektedir.

\section{Sonuçlar}

Alınan numunenin SEM, EDS, XRF ve XRD analizleri yapılmış ve her analizin TS EN ISO 11126-4 tanımlanan kömür cürufu griti malzemesiyle aynı olduğunu doğrular nitelikte sonuçlar elde edilmiştir. Standartta termik santral yan ürünü olan kömür cürufunun grit olarak kullanılması için gerekli özellikler belirlenmemiştir.

Yapılan analizler incelenen ürünün TS EN ISO 11126-4 standardında belirtilen kömür cürufu griti özellikleri taşıdığı tespit edilmiştir. Dolaysıyla Ukrayna'dan ithal edilen termik santral yan ürünü Türkiye'de Kömür cürufu griti olarak kullanılabilir.

Mikro kürecikler düşük yoğunlukta olduğundan, iç boşlukları izolatör gibi davranacağından, döküm sektöründe ekzotermik besleyici ve mini besleyici hammaddesi olarak kullanılabileceği anlaşılmıştır.

\section{Kaynaklar}

[1] Dziadula, S., \& Kosalka, J. (2013, January). Experience gained during modernization of $200 \mathrm{MW}$ powerunits ( $\mathrm{nr} 2$ and 4) in the electric power station Elektrownia Jaworzno III. Energety ka, 703 , pp. 12-14.

[2] Fenelonov V.B. (2010). The Properties of Cenospheres and the Mechanism of Their Formation During High-Temperature Coal Combustion at Thermal Power Plans. KONA Powder and Particle Journal 28, 89-207.

[3] Fleming D., (2012). Analysis on Characteristics of Fly Ash from Coal Fired Power Stations. Energy Procedia 17 , pp. 3-9.

[4] Fomenko, E. (2011). Fly Ash Cenospheres: Composition, Morphology, Structure, and Helium Permeability. World of Coal Ash Conference. Denver.

[5] Kolay P.K. (2001). Physical, chemical, mineralogical, and thermal properties of cenospheres from an ash lagoon. Cement and Concrete Research 31 , 539-542.

[6] Petrus, H. T. (2011). Performance of dry-separation processes in the recovery of cenospheres fromfly ash and their implementation in a recovery unit. International Journal of Mineral Processing 98, pp. 15-23.

[7] Vassilev, S. T. (2004). Phase-mineral and chemical composition of coal fly ashes as a basis for their multicomponent utilization. 2. Characterization of ceramic cenosphere and salt concentrates. Fuel 83, pp. 585-603.

[8] Wang, C., Liu, J., Du, H., \& Guo, A. (2012). Effect of fly ash cenospheres on the microstructure and properties of silica-based composites. Ceramics International 38 , 4395 4400. 